\title{
Teaching Statistics to MSW Students: Comparing Credit and Non-Credit Options
}

\author{
Ashley Davis \\ Rebecca G. Mirick
}

\begin{abstract}
In professional disciplines like social work, students are expected to be able to understand and apply basic statistical concepts. Graduate programs differ in how they expect students to develop this ability; some require a full-credit statistics course as a prerequisite to admission, and others incorporate statistics into social work research courses. The for-credit requirement has a high financial and time cost for students. This exploratory study examined the feasibility of replacing this requirement with a brief, noncredit statistics course. MSW students $(n=168)$ who took both types of courses were surveyed. No association was found between the type of course and students' anxiety, confidence, and the perceived relevance of statistics. Students identified factors that impeded or facilitated their learning. The inclusion of the statistics course within the social work program and the use of relevant social work literature was perceived as supporting students' learning of statistics. The course length was no more of a concern for the noncredit statistics students than for the for-credit students. These findings support the use of a brief, non-credit statistics course as a less costly and time-consuming approach, but raises concerns about consistently high levels of anxiety, and low levels of confidence and statistics ability of MSW students.
\end{abstract}

Keywords: Statistics; research; teaching approaches; MSW students

In professional disciplines, statistical knowledge and skills are needed to be effective in practice and policy work. Within the field of social work, statistics are used to understand and critique empirical research, evaluate practice, disseminate research findings, and promote clients' interests (Capshew, 2005; Wells, 2006). When students have developed statistical literacy, they can appropriately apply statistical concepts and accurately use these skills (Ramirez, Schau, \& Emmioglu, 2012), which help them engage in evidence-based practice, policy initiatives, and research endeavors.

The development of MSW students' statistical literacy differs by program. For many programs, an introductory statistics course is a pre-requisite for admission (Elliott, Choi, \& Friedline, 2013). Students may have taken a statistics course during their undergraduate coursework. Those students who did not already take a statistics course often need to take one at another university before entering their graduate program. This requirement can be inconvenient to fulfill due to work or family obligations and can be a financial burden as well. Many of these students complete a statistics requirement in a "service course," which is taught within a math or statistics department outside of their professional discipline (Gordon, 2004). Perhaps due to inconveniences or negative feelings about statistics, it is not uncommon for students to avoid completing a required statistics course for as long as they can (Macheski, Buhrmann, Lowney, \& Bush, 2008).

Ashley Davis, PhD, MSW is an Assistant Professor, Department of Social Work, Wheelock College, 200 Riverway, Boston, MA, 02215. Rebecca G. Mirick, PhD, MSW is an Assistant Professor, School of Social Work, Salem State University, 352 Lafayette St., Salem, MA, 01970. 
It is important to identify and explore possible ways that students can become proficient in statistics and the effectiveness of these various approaches at teaching statistical literacy. A prerequisite statistics courses may cover a range of concepts that may or may not be the most useful for social work students; such courses may vary as to whether they prioritize computations or conceptual understanding and application. When taking a prerequisite course, students may struggle to see the necessity or relevance of the material to their social work education, and may experience the course as disjointed from the rest of their graduate studies (Bolen, 2006). Some MSW programs do not insist that students complete a pre-requisite, but instead incorporate statistics into the curriculum. Research courses are the logical place to teach statistical concepts, although many students already experience trepidation about and disinterest in research (Bolin, Lee, GlenMaye, \& Yoon, 2012). Students' anxiety and reluctance could be heightened by the addition of statistics to the content of a research course.

To address these issues, some social work programs offer a brief, non-credit bearing statistics course. While program administrators and faculty members may make assumptions about the benefits and limitations of a brief, non-credit bearing statistics course, research has not studied the efficacy of this teaching approach in comparison with more traditional, full-semester, for-credit statistics courses. This study examined whether there was any association in attitudes and feelings about statistics, or differences in statistical ability between those students who took a brief, non-credit bearing statistics course within their social work graduate program and those who completed a full-semester, for-credit statistics course prior to beginning their graduate studies in social work.

\section{Literature Review}

Within the United States, professional organizations and accrediting bodies emphasize the importance of research to practice, including the use of quantitative methods. In its Code of Ethics, the National Association of Social Workers (2008) admonishes social workers to "critically examine and keep current with emerging knowledge relevant to social work and fully use evaluation and research in their professional practice" (sect. 5.02). Students develop the ability to fulfill this ethical imperative through their social work education. In courses on research and evaluation, they receive training in qualitative and quantitative methods that are used to produce evidence-based findings for enhancing social work practice, policy, and service delivery (Council on Social Work Education, 2015). Social workers need to possess statistical knowledge and skills to critically analyze the professional literature, skillfully evaluate their own practice, and best serve their clients (Harder, 2010). When graduates of social work programs develop an appreciation and understanding of basic statistical concepts, Marson (2007) suggests: "great advances in the knowledge base and the evaluation of social work practice are sure to follow" (p. 211). This hopeful perspective is tempered by Knight's (2015) findings that, despite feeling prepared by social work education to engage in evidence-based practice, many graduates do not employ this practice behavior, avoid literature that describes research, and do not understand the discussion of statistics in research articles.

Despite the ethical imperative, curricular mandate, and ubiquity of statistics, social work instructors face challenges in preparing students to develop the knowledge and skills 
needed for research methods and statistics. Social work students are commonly referred to as avoidant, anxious, or reluctant learners of statistics (Capshew, 2005; Junius \& Siddell, 2009; Marson, 2007). Lalayants (2012) reviewed what is known about the effects of students' attitudes toward statistics. Associations were found between students' anxiety and negative emotions and their learning, including their openness to learn, development of statistical thinking, application of knowledge in the field, and understanding of quantitative studies in the professional literature. Even within social work education, there is a particularly complex relationship between students' statistics knowledge and their attitudes about research courses; increased statistical knowledge was correlated with reduced fear of research courses, but not with greater appeal of research courses (Secret, Ford, \& Rompf, 2003).

Students in the social sciences commonly experience anxiety in learning about statistics (Pan \& Tang, 2005). This anxiety may be particularly strong for social work students (Thomas, 2008). Onwuegbuzie and Wilson (2003) categorized factors associated with statistics anxiety as situational, dispositional, or personal. These categories echo throughout the social work literature on statistics anxiety. For example, Elliott at al. (2013) noted situational factors, including the limited number of math courses that social work students take as undergraduates, or the minimal time that gets devoted to research and statistics content in social work education. Junius and Sidell (2009) focused on dispositional factors, such as the need to help students increase their motivation and ownership of learning statistics. Davis (2003) is among the researchers who have explored personal factors, including the higher levels of statistics anxiety among female and minority social work graduate students.

While anxiety is a common barrier to learning statistics, a typical social work graduate course includes a "blend of students from more to less interested, anxious, and capable" (Bolen, 2006, p. 19) with statistics, and instructors often find it challenging to teach to such a range of feelings and abilities. Students' anxiety about statistics can be affected by teaching strategies, classroom climate, and instructor qualities (Lalayants, 2012). These factors are important to understand because they are within an instructor's control and can be incorporated into the design, structure, and teaching style of a course.

\section{Teaching Strategies}

The empirical literature is replete with approaches for teaching statistics to students in professional education. Instructors do not need to pick only one teaching strategy (Secret et al., 2003), but can apply several approaches flexibly and responsively. The pacing and delivery of material can be intentional, such as using repetition, providing immediate feedback (Marson, 2007), or flipping the classroom by using class time to apply material learned outside of class (Wilson, 2013). Similarly, problem-based learning models (Junius \& Sidell, 2009), peer-led team learning (Curran, Carlson, \& Celotta, 2013), and servicelearning research projects (Wells, 2006) create hands-on, interactive learning opportunities. These collaborative approaches encourage students to relate to their instructor as a mentor and resource person, instead of the traditional role of lecturer.

These teaching strategies suggest innovative approaches for helping students learn 
statistics, and yet, there is a dearth of empirical literature evaluating their effectiveness in improving students' knowledge and abilities. Elliott and colleagues (2013) measured changes in MSW students' ( $\mathrm{n}=25)$ perceptions after completing an online statistics lab concurrent with their research methods course. Students perceived themselves to be more confident in their knowledge of statistics, their use of this knowledge to enhance practice, and their comprehension of scholarly articles. Similarly, Wells (2006) used course evaluations to capture MSW students' (n=38) perceptions. Students described servicelearning projects as a "purposeful" (p. 401) way to learn statistics with real data sets, and reported that they would be "less fearful" (p. 400) about using these skills in the future. In two studies that measured changes in statistical competence, the use of a flipped classroom (Wilson, 2013) and peer-led learning teams (Curran et al., 2013) were both found to be effective with undergraduates, compared to a course taught using traditional methods.

Calderwood (2002) urges that statistics instruction should be modeled after reality, in which practitioners do not memorize formulas or perform calculations by hand. Instead, students should be expected to understand the meaning and purpose of statistical tests, and develop the ability to read and critically appraise quantitative findings in scholarly articles (Rabin \& Nutter-Upham, 2010). Students should know how to use available resources, such as computer applications (Wells, 2006) or colleagues who are statisticians, to support their work and make statistics more user-friendly (Stickels \& Dobbs, 2007).

\section{Classroom Climate}

A well-structured, nonthreatening learning environment can mitigate students' reluctance to learn statistics (Lalayants, 2012). In the beginning of the course, instructors may find it helpful to acknowledge students' range of feelings. Students often anticipate "boring, dry material" (Capshew, 2005, p. 860), but instructors can teach in ways that contradict this expectation, set an upbeat, interactive tone, and incorporate fun activities (Lesser et al., 2013). Students may continue to find the course challenging, but can be socialized to see that "having fun can mix with the difficult subject matter" (Macheski et al., 2008, p. 44). Other instructors might focus less on making statistics enjoyable for reluctant learners because students can increase their statistical knowledge without improving their attitude about the subject (Sizemore \& Lewandowski, 2009).

\section{Instructor Qualities}

Instructors can engage students in ways that promote statistics learning. They can bring humor to the topic, which is especially useful in engaging students who hold negative attitudes about statistics (Neumann, Hood, \& Neumann, 2009). Connections with students outside of the classroom positively affect learning. McGrath (2014) explored the role of instructors' office hours in student success; students who met with an instructor and engaged in self-assessment improved their performance. Classroom assessment techniques are another tool with which instructors can encourage students to assess their developing competence and offer feedback about the course (Goldstein, 2007). This approach provides ongoing communication between the instructor and students, which can serve to strengthen their relationship. 


\section{The Efficacy of Different Approaches}

Learning statistics knowledge and skills may not equate to being statistically literate (Ramirez et al., 2012). In subsequent courses and later in the field, students should be able to recall and apply what they have learned, and even recognize when they need additional training to further their skills. Barnett and Ceci's (2002) taxonomy of transfer may explain the challenge with reaching statistical literacy. "Near transfer” refers to students' abilities to learn and use new material, and thus successfully pass an introductory course; "far transfer" includes the ability to develop "skills that extend beyond the performance in the class in which they were acquired" (Daniel \& Braasch, 2013, p. 201). This theory may explain Secret et al's (2003) findings: despite having completed an introductory statistics course, the majority of social work students in their sample were unable to demonstrate statistical knowledge.

There are contextual factors that affect transfer, including the knowledge domain, temporal context, and functional context (Barnett \& Ceci, 2002). Knowledge domain, or the knowledge base to which the skill is applied, is a relevant factor since most social work students do not take statistics as part of their graduate education. The temporal context refers to the time elapsed between learning and being tested on new concepts. Many students successfully pass a course during their undergraduate program, but experience erosion of knowledge by the time they pursue a graduate degree, take other courses, or begin working after graduation. Finally, the functional context relates to whether the academic learning carries over to the field. Professional education often involves the acquisition of skills in the classroom that are then applied in the field. It may be especially important for students to learn statistics in ways that can be applied in practice contexts, such as grasping the underlying concepts rather than memorizing formulas (Calderwood, 2002; Gordon, 2004).

\section{Learning Statistics within Social Work Education}

There are benefits to a statistics course offered within the discipline. When social work students have a statistics instructor who is also a social worker, they have an opportunity to see a member of their profession who is comfortable, confident, and competent with this material. Students may also be more likely to view the material as relevant. Unlike a service course, a statistics course offered within professional education would likely use examples from empirical studies that are related to practice. Moran (2005) noted that often statistics courses are taught differently from the core courses within the discipline. Statistics could be taught in ways that are similar to other professional courses, such as emphasizing how statistics could be used to advocate for clients, analyze social justice issues (Lesser, 2007), or "utilizing [students'] own ideas as the medium for analyses throughout the course" (Bolen, 2006, p. 20). The similarities and overlap in method and content could help students see that statistics are indeed important and relevant to the rest of the curriculum. In a professional discipline, the most important motivator to learn is a relevant connection to the field (Bolen, 2006; Davis \& Mirick, 2015]; Lalayants, 2012).

This article describes the attitudes, levels of anxiety and confidence, and ability of students who took an accelerated brief, non-credit bearing statistics course within their 
social work graduate program compared to students who took a full-semester, for-credit course. The study addressed the following research questions: Was there an association between the type of statistics course (i.e., accelerated statistics course offered within a social work graduate program versus undergraduate statistics course) and students' anxiety, confidence, and belief in relevance to social work education and practice? Was there any difference in ability to apply statistical knowledge after the course? What factors do students self-report as facilitating or hindering statistical learning? Is there an association between type of statistics course and the factors perceived to facilitate or hinder statistical learning?

\section{Method}

\section{Participants}

Participants were enrolled in a graduate social work program at a small, accredited, private, urban school in the United States. Traditionally, the program required a statistics course taken within the past five years and with a minimum grade of a C. In 2013, the program began offering an accelerated three-week, non-credit option taught by a full-time social work faculty member for students who did not have this statistics prerequisite. This course consists of four 3-hour face-to-face sessions and two hours of online work. The course focused on understanding statistical concepts and interpreting implications of findings, instead of mathematical formulas. The course material included descriptive (percentages, frequencies, measures of central tendency, measures of dispersion) and inferential analyses (t-tests, Chi square, correlation, ANOVA, and regression), with an emphasis on the role of hypothesis-testing in determining statistical significance. In class, the instructor engaged students with interactive PowerPoint lectures with responseware "clickers," and used small group exercises to apply the concepts. In each class session, students were assessed on their understanding of the cumulative concepts. Outside of class, students completed homework assignments, contributed to online discussion forums, and completed assigned readings. In addition to an introductory textbook (Pryczak, 2014), students read several articles from the social work literature that reported on empirical studies using quantitative methods. These pieces provided relevant and relatable examples of how social workers use statistics to answer research questions and inform practice and policy. Students developed the ability to read statistical findings presented in narrative and table formats, and consider possible social justice-based implications.

The sample consisted of 168 MSW students who completed the survey at the end of their required social work research course. Forty-five (27\%) students had taken the brief, non-credit statistics course, and 123 (73\%) took a for-credit statistics course prior to entering the program. Of those students who took a for-credit course, $75 \%(n=92)$ took the course during their undergraduate program and $24 \%(n=29)$ took statistics after earning their undergraduate degree (missing $=2$ ).

\section{Measures}

Data were collected on students' experiences learning statistics, their attitudes about statistics, levels of anxiety and confidence about statistics, and their statistical ability. 
Students were asked to report where they took statistics (e.g., the non-credit course or a full-credit course) but no other sample characteristics were obtained.

Experiences learning statistics. Participants were asked: "Which factors supported your development of statistics knowledge and skills?” Students were given a checklist of six factors and asked to select all that related to their experience of learning statistics. The six supporting factors were: 1) course was taught within the social work program, 2) relevant journal articles were used as examples, 3) instructor's teaching style supported students' understanding of the material, 4) material was presented in multiple formats, 5) collaboration among peers was encouraged in the classroom, 6) material was reviewed to reinforce previous concepts before introducing new ones.

Participants were asked: "Which factors of the course impeded your development of statistics knowledge and skills?” Students were given a checklist of six factors and asked to select all that applied. The six impeding factors were: 1) the statistics material taught was not in-depth enough, 2) material was taught at too advanced a level, 3) the workload was too much, 4) the instructor was not accessible to students, 5) the class size was too big, and 6) connections were not made between statistics and implications for social work practice and policy.

These factors were chosen because the literature on statistical learning identifies them as factors that can impede or facilitate learning. Additional factors were added because they reflected anticipated or assumed benefits or drawbacks of a brief, non-credit statistics course offered within the social work program. While the measure has strong face validity, other types of validity or reliability have not been determined.

Attitudes, beliefs, and feelings about statistics. Four 4-point Likert scale questions (1=strongly disagree, $2=$ disagree, $3=$ =agree, 4=strongly agree) were used to determine the extent to which participants agreed or disagreed that: 1) statistics were relevant to social work education, 2) statistics were relevant to social work practice, 3) they felt anxious about statistics, and 4) they felt confident about statistics. Participants were asked whether anxiety was alleviated by the course with possible responses of yes, no, or not anxious.

Statistical ability. Participants matched five statistical terms (frequency, median, mean, standard deviation and chi-square) to definitions. Five additional questions required participants to identify a paired t-test and interpret a paired t-test, median, and Pearson correlation (see Appendix A). The author who taught social work research at the institution developed the questions that include knowledge that the research instructors expect students possess after taking an introductory statistics course. Correct answers were given a score of 1 . Incorrect answers were given a score of 0 . These answers were summed (total possible score $=10$ ) to calculate the statistics ability score.

\section{Procedure}

Data were collected from spring 2014 to spring 2015 through an anonymous, one-time, paper-and-pencil survey. After the research project was approved by the university's IRB, a research assistant or the author who was not a faculty member at the institution visited social work classes to introduce the study and distribute surveys. Students were informed 
that participation was voluntary and anonymous. Students who were absent did not have an opportunity to participate. Out of 217 possible participants, 170 (78\%) took surveys. Two were incomplete, with only the first page filled out. These two surveys were dropped from the analyses, leaving a total $n$ of 168.

\section{Analyses}

Statistical analyses were performed with IBM Corporation (2012) SPSS statistics 21. Descriptive statistics (mean and standard deviation, frequency and percent) explored anxiety, confidence, and perceived relevance of statistics towards education and practice. With a four-point Likert scale, the responses were not normally distributed, so these responses were re-coded into a dichotomous variable (1=agree/strongly agree, $0=$ disagree/strongly disagree). Chi-square analyses were used to look for associations between anxiety, confidence, knowledge and the belief that statistics are relevant to social work education and practice and the learning context (i.e., the accelerated, in-program course versus a course taken outside of the social work program). Frequencies were used to describe the factors that supported and/or impeded students' learning. Chi-square tests were applied to look for associations between statistics learning context and the factors participants identified as supporting or impeding their learning of statistics. A t-test was used to determine if there was a difference in statistical ability based on statistics learning context. All hypothesis tests were performed at the 0.05 level.

\section{Findings}

\section{Anxiety, Confidence, Knowledge, Belief in Relevance, and Ability}

All participants $(\mathrm{n}=168)$ responded to questions about anxiety, confidence, knowledge and relevancy. Nearly two-thirds $(63 \%)$ of participants $(n=105)$ agreed they felt anxious about statistics and 49 (29\%) indicated they felt confident about statistics. One hundred twenty-one (72\%) agreed that statistics was relevant to their social work education, and 144 (86\%) agreed that statistics was relevant to their social work practice. Only 120 students (71\%) completed the statistics ability measure; the average score was 6.68 $(S D=2.31)$ out of a possible total score of ten. The internal consistency of this scale was acceptable (Cronbach's alpha $=0.76$ ).

\section{Perception of Factors that Affected Learning}

The most common factors that supported learning were instructor's teaching style ( $n=92,55 \%)$, material presented in multiple formats $(n=80,48 \%)$, and review of material to reinforce concepts $(n=78,46 \%)$. The most common factors that hindered learning were a lack of connection between statistics and implications for social work practice or policy $(43 \%, n=72)$, the workload $(21 \%, n=35)$, and statistics material being insufficiently indepth $(19 \%, n=32)$. See Table 1. 
Table 1. Factors that Support and Hinder Statistics Learning $(n=168)$

\begin{tabular}{lr}
\hline & $f(\%)^{\mathrm{a}}$ \\
\hline Factors supporting learning & $92(55 \%)$ \\
Instructor's teaching style supported students' understanding of the material & \\
Material was presented in multiple formats (lecture, PowerPoint, readings etc.) & $80(48 \%)$ \\
Material was reviewed to reinforce previous concepts before introducing new & $78(46 \%)$ \\
$\quad$ ones & $62(37 \%)$ \\
$\quad \begin{array}{l}\text { Relevant journal articles were used as examples } \\
\text { Course was taught within the social work program }\end{array}$ & $55(33 \%)$ \\
$\quad$ Collaboration among peers was encouraged in the classroom & $54(32 \%)$ \\
Factors impeding learning & $72(43 \%)$ \\
$\quad$ Connections were not made between statistics and implications for social work & \\
$\quad$ practice and policy & $35(21 \%)$ \\
The workload was too much & $32(19 \%)$ \\
The material was not in-depth enough & $26(16 \%)$ \\
Material was taught at too advanced a level & $24(14 \%)$ \\
The class size was too big & $21(13 \%)$ \\
\hline The instructor was not accessible enough to students & \\
\hline
\end{tabular}

\section{Anxiety Reduction}

One hundred sixty-three (96\%) participants responded to a question that asked if their statistics course alleviated anxiety about statistics. Seventy-nine percent $(n=133)$ reported having some anxiety about taking a statistics course prior to the start of the course. Fortyfour percent $(n=73)$ did not find the course alleviated their anxiety, 36\% $(n=60)$ reported their anxiety was alleviated, and $18 \%(n=30)$ were not anxious.

\section{Comparisons Between Course Type}

There were no statistically significant associations between course type and anxiety, $\chi^{2}(1, \mathrm{n}=168)=1.07, p=0.30$, confidence, $\chi^{2}(1, \mathrm{n}=168)=0.66, p=0.42$, or belief that statistics are relevant to social work education, $\chi^{2}(1, n=168)=0.68, p=0.41$, or practice, $\chi^{2}(1$, $\mathrm{n}=168)=2.14, p=0.14$ (see Table 2). There was no significant association between the type of course taken and whether the course relieved students' anxiety about statistics for students who reported they were anxious entering the course, $\chi^{2}(1, n=132)=3.07, p=0.80$. There was no significant difference in statistical ability between the for-credit course $(M=6.94, S D=2.55, \mathrm{n}=34)$ and the non-credit course $(M=6.57, S D=2.21, \mathrm{n}=85)$, $t(117)=0.804, p=0.42$.

As many $(n=49)$ of the responses for statistical ability were missing on surveys which were otherwise complete, a missing data analysis compared those with missing data to those without. There was no association between missing data and type of course taken, $\chi^{2}(1, \mathrm{n}=168)=0.66, p=0.42$, anxiety, $\chi^{2}(1, \mathrm{n}=168)=0.004, p=0.95$, confidence, $\chi^{2}(1$, $\mathrm{n}=168)=0.10, p=2.79$, knowledge $\chi^{2}(1, \mathrm{n}=168)=0.24, p=0.62$, or belief in relevance of statistics to social work education, $\chi^{2}(1, \mathrm{n}=168)=0.11, p=0.74$, or practice $\chi^{2}(1$, $\mathrm{n}=168)=0.40, p=0.53$. 
Table 2. Comparison of Feelings and Attitudes towards Statistics by Course Type ( $n=168)$

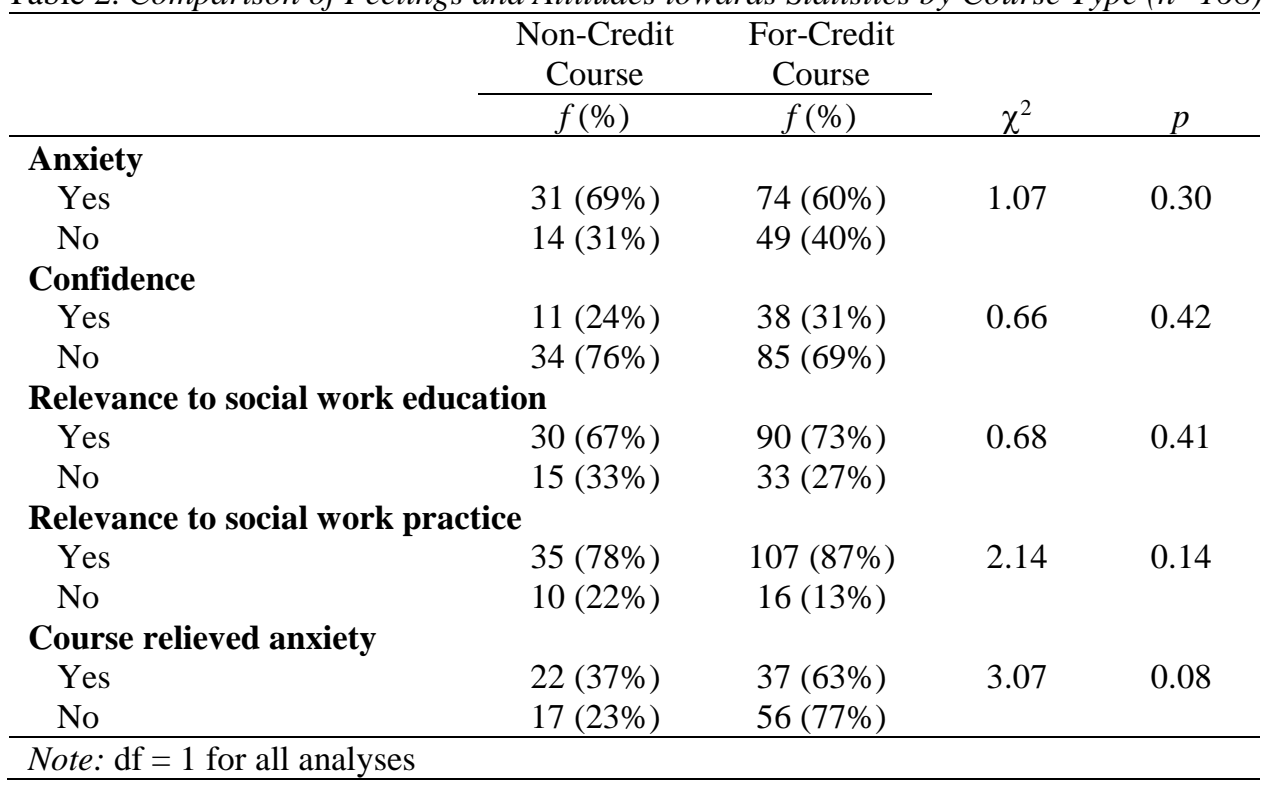

There were significant associations between course type and identifying the use of relevant journal articles with statistical examples, $\chi^{2}(1, \mathrm{n}=166)=5.48, p=0.02$, and the fact that their course was taught within the social work program, $\chi^{2}(1, \mathrm{n}=166)=41.87, p<0.001$, as supporting their learning. There was a significant association between course type and the identification of a lack of connection between statistics and social work practice and policy, $\chi^{2}(1, \mathrm{n}=166)=10.65, p<0.001$, as a barrier to learning. There were no significant associations between course type and any other factors supporting or hindering learning, including the depth of material covered in the course, $\chi^{2}(1, \mathrm{n}=166)=1.35, p=0.25$ (see Table $3)$.

\section{Discussion}

Overall, there were no differences in students' feelings and attitudes towards statistics based on the type of course taken. There was no significant association between feelings or attitudes towards statistics or statistical ability and the type of statistics course nor were there any significant differences in students' ability to apply statistical concepts. Students who took the accelerated, non-credit statistics course were equally able to use statistics, and no more anxious or less confident because they spent less time in a statistics course. In fact, students in the non-credit course were no more likely to endorse the lack of depth of the course as a barrier to their learning than those who took the full-credit course, suggesting that students do not perceive the shorter length of the course as detrimental to their learning. Students appear able to learn statistics in a variety of contexts and with different teaching strategies, which is consistent with literature on instruction in introductory statistics courses (Curran et al., 2013; Wilson, 2013). 
Table 3. Supports and Barriers to Learning Statistics for Students by Course Type

\begin{tabular}{|c|c|c|c|c|}
\hline & $\begin{array}{c}\begin{array}{c}\text { Non-Credit } \\
\text { Course }\end{array} \\
f(\%)\end{array}$ & $\begin{array}{c}\begin{array}{c}\text { For-Credit } \\
\text { Course }\end{array} \\
f(\%)\end{array}$ & $\chi^{2}$ & $p$ \\
\hline \multicolumn{5}{|c|}{ Course in Social Work program } \\
\hline Yes & $32(71 \%)$ & $22(18 \%)$ & 41.87 & $<0.001$ \\
\hline No & $13(29 \%)$ & 99 (82\%) & & \\
\hline \multicolumn{5}{|c|}{ Relevant journal articles } \\
\hline Yes & $23(51 \%)$ & 38 (31\%) & 5.48 & 0.02 \\
\hline No & $22(49 \%)$ & $83(69 \%)$ & & \\
\hline \multicolumn{5}{|c|}{ Instructor's teaching style } \\
\hline Yes & $30(67 \%)$ & $61(50 \%)$ & 3.50 & 0.6 \\
\hline No & $15(33 \%)$ & $60(50 \%)$ & & \\
\hline \multicolumn{5}{|c|}{ Material in multiple formats } \\
\hline Yes & 24 (53\%) & 65 (54\%) & 0.65 & 0.42 \\
\hline No & $21(47 \%)$ & $56(46 \%)$ & & \\
\hline \multicolumn{5}{|c|}{ Collaboration encouraged } \\
\hline Yes & $18(40 \%)$ & $36(30 \%)$ & 1.57 & 0.21 \\
\hline No & $27(60 \%)$ & $85(70 \%)$ & & \\
\hline \multicolumn{5}{|c|}{ Review of material } \\
\hline Yes & $24(53 \%)$ & $53(44 \%)$ & 1.20 & 0.27 \\
\hline No & $21(47 \%)$ & $68(56 \%)$ & & \\
\hline \multicolumn{5}{|c|}{ Lack of connection with practice/policy } \\
\hline Yes & $10(22 \%)$ & $61(50 \%)$ & 10.65 & $<0.001$ \\
\hline No & 35 (78\%) & $60(50 \%)$ & & \\
\hline \multicolumn{5}{|c|}{ Material not taught in depth } \\
\hline Yes & $11(24 \%)$ & $20(17 \%)$ & 1.35 & 0.25 \\
\hline No & $34(76 \%)$ & $101(84 \%)$ & & \\
\hline \multicolumn{5}{|c|}{ Material too advanced } \\
\hline Yes & $8(18 \%)$ & 17 (14\%) & 0.36 & 0.55 \\
\hline No & 37 (82\%) & $104(86 \%)$ & & \\
\hline \multicolumn{5}{|c|}{ Workload too heavy } \\
\hline Yes & $10(22 \%)$ & 25 (21\%) & 0.05 & 0.83 \\
\hline No & 35 (78\%) & 96 (77\%) & & \\
\hline \multicolumn{5}{|c|}{ Instructor inaccessibility } \\
\hline Yes & $2(4 \%)$ & 19 (16\%) & 3.76 & 0.05 \\
\hline No & $43(96 \%)$ & $102(84 \%)$ & & \\
\hline \multicolumn{5}{|c|}{ Class size too big } \\
\hline Yes & $4(9 \%)$ & 20 (17\%) & 1.55 & 0.21 \\
\hline No & 41 (91\%) & $101(83 \%)$ & & \\
\hline
\end{tabular}

These results may reflect the fact that the length of the course is only one factor in learning new material. The students who took the non-credit course were more likely to endorse that the following factors facilitated their learning: having the course was offered within the social work program, taught by a social work instructor, and using relevant, social work articles. In contrast, students who took the for-credit statistics prerequisite were more likely to identify a lack of connection between statistics and social work as a barrier to their learning. There may be a benefit to waiting to develop this knowledge and skill set 
until graduate school, and learning and applying statistics within the same knowledge base, which is their professional discipline. Indeed, previous studies have shown that MSW students find statistics learning to be meaningful, relevant, and applicable when connected to practice settings and their coursework (Elliott et al., 2013; Wells, 2006).

By taking the non-credit course, students may have benefited from instructors' familiarity with social work practice and values, and their own beliefs about the relevance of social work research (Barretti, 2004). Scholarly articles may relate to topics students are familiar with and interested in, and therefore, they may be motivated to read the material closely and understand it thoroughly (Bolen, 2006; Lalayants, 2012; Rabin \& NutterUpham, 2010). Relevant journal articles may become another vehicle for connecting the material to the discipline, which increases the likelihood of "far transfer" (Barnett \& Ceci, 2002, p. 612; Daniel \& Braasch, 2013). Using the concepts from Barnett and Ceci's (2002) taxonomy of transfer, the students in the for-credit course were more likely to have learned statistics apart from the knowledge base to which the skill is applied.

It is concerning that regardless of where students took statistics, the majority of students remained anxious, not confident, and demonstrated a low ability to use and apply statistics. Over three-quarters (79\%) of the students endorsed some anxiety about learning statistics before entering the course. This finding is consistent with the literature that emphasizes social work students' anxiety about statistics (Capshew, 2005; Junius \& Siddell, 2009; Marson, 2007). However, 44\% of students did report that taking a statistics course alleviated their anxiety. Once students begin learning statistics, some appear to find it less overwhelming, and their anxiety dissipates. Students identified several reasons for their lessened anxiety: instructor qualities (e.g., being knowledgeable, patient, and kind), teaching approaches (e.g., normalizing anxiety, making material relevant), and the perception of the course as less overwhelming than expected. There were no differences between learning contexts; it may be that, as with anxiety about graduate school in general, students' anxiety tends to lessen once they have taken a course and start to know the unknown (Gelman, 2004). While almost half (44\%) of these anxious students experienced a decrease in anxiety after taking the course, by the time of this survey, 63\% reported being anxious about statistics. Clearly, anxiety about statistics is prevalent for students in this MSW program.

Of even more concern than student anxiety is the low level of ability to use and apply statistics ( $M=6.68$ out of a possible 10), demonstrated by all the students in this sample, regardless of the type of statistics course. This reflects previous findings by Secret et al. (2003) who found that levels of ability to use statistics remained low even after the course was completed. Being able to understand, use, and apply statistics is an important component of many social work jobs and is necessary for consuming professional research, managing and tracking program statistics, and evaluating programs for effectiveness and/or grant funding. This finding suggests that most graduate social work students need more instruction in statistical concepts; determining how to do this in ways that are effective and feasible should be a focus of future research in this area. 


\section{Limitations}

There were several limitations of this study. The participants who attended the inprogram course were enrolled in just one social work graduate program, and therefore, caution should be taken in generalizing the findings to other in-program statistics courses. Students' attitudes and statistical ability may be related to how statistics is, or is not, incorporated in the social work curriculum in that program. The number of individual statistical analyses used in this research study leads to an increase in the likelihood of type1 errors; this suggests the possibility that some of the significant findings might be the result of a type- 1 error.

The cross-sectional design of the study, while practical, makes it impossible to determine whether there were significant differences between the students who took the non-credit course and those who entered the program having already taken statistics. There was no way to determine whether one group entered with higher levels of anxiety, less experience with math, or a great number of years between their undergraduate program and their graduate program. In fact, some of the assumptions of differences between the two groups may not have been true for all students. For example, while this research project assumed that the for-credit students did not learn statistics within their discipline, in all likelihood, this is not true for some of the students, who might have been social work or psychology students and therefore, learned statistics in their undergraduate program within the context of their discipline, just as the non-credit statistics students did in this graduate program.

The measures that were used were developed for this project, so determinations of reliability and validity are preliminary. While the measures have face and content validity, test/re-testing is required in order to evaluate whether the measures produce reliable, consistent results over time. The measure of internal consistency for statistical ability was adequate (Cronbach's alphas $=0.756$ ) suggesting that, although the survey was brief, it adequately measured a unidimensional construct. With the overall low scores on the measure of ability to apply statistics, a lengthier survey would have been more effective as it would be more sensitive to small differences between groups. The sample size for the group of students that took the accelerated, in-program statistical course, was small $(n=45)$. This may have impacted the power of the study and whether significant results were found. A future study using a larger sample size could validate the findings in this study. Despite the limitations, these preliminary findings highlight important information about feasible options for statistical learning, which are less costly and time-consuming than a for-credit prerequisite.

\section{Implications}

Students taking the brief, non-credit statistics course appear to leave the course with similar feelings and attitudes towards statistics, and a similar ability to apply statistical knowledge, as students who took a full-semester, for-credit course. This finding is important for social work graduate programs because brief courses, like this one, may be a convenient, time- and cost-effective option for students who have not already completed this pre-requisite in their undergraduate program. These courses have the benefits of being 
able to consciously connect statistics with practice, which students in this study identified as facilitating their learning of statistics. These findings suggest that social work graduate programs that currently require a statistics prerequisite might consider the development of a brief, non-credit option within the social work department, especially if their students experience the statistics pre-requisite as a financial or time burden.

A substantial number of social work students (63\%) remain anxious about the material after the course is completed, and it is important for social work programs to consider how to address this anxiety in their students. However, it is noteworthy that, prior to the start of the course, some students (11\%) were not anxious about statistics. This finding indicates a wide diversity in feelings about statistics, from not at all anxious beginning the course to anxious about statistics even after successfully completing the course. Instructors need to assume a wide variation in students' attitudes, rather than a universal aversion toward research and statistics (Secret et al., 2003). Incorporating this into statistical course planning might improve feelings, attitudes, and ability for all students, not just those who are extremely anxious.

Regardless of the context for learning statistics, many students struggled to retain the material they have learned. They demonstrated "near transfer" (Barnett \& Ceci, 2002, p. 615), or gaining enough knowledge to pass an introductory course, but had considerable erosion of knowledge afterward. In order to retain their knowledge, students may need frequent opportunities to review and integrate the material more fully. These opportunities can be provided throughout the curriculum, such as incorporating statistics within research methods courses, using statistics to show the efficacy of evidence-based practice models, analyzing statistics used in policies and advocacy work, and including the use of statistics in field placements. In this way, statistics are not set apart from the rest of the curricular content. This approach also models the instruction after reality; rather than the mathematical computations, students learn the meaning, purpose, and utility of statistical tests (Calderwood, 2002). Additionally, instructors may select examples related to social justice issues that students care about (Lesser, 2007); this focus can increase student engagement, motivation, and interest, and may make the content particularly relevant for students pursuing a profession aimed at addressing inequities.

Instructors can note the factors that students identified as facilitating or hindering their learning. Students valued having the material presented in multiple formats and being reinforced through repetition and review. Some of these factors were echoed in the ways that their course lessened their anxiety, such as making the content relevant and engaging students with clickers. Clickers encourage students to pay attention and actively participate, without the embarrassment of getting a question wrong or admitting not knowing an answer (Smith, Shon, \& Santiago, 2011), which is important within a class where many students report anxiety and lack of confidence with the material. Clickers provide immediate feedback and are a technologically savvy version of the classroom assessment technique that Goldstein (2007) encouraged in introductory statistics courses. 


\section{Conclusion}

This study evaluated the use of a brief, non-credit statistics course in place of a requirement for a full-length, for-credit course. This option is a time- and money-saving solution for students who did not take, or successfully complete, an introductory statistics course during their undergraduate education. Findings suggest this is a comparable alternative for MSW students in terms of anxiety, confidence, and ability to apply statistics. The findings suggest that students identify benefits of a non-credit statistics course, including its location within the social work program and the use of relevant journal articles. While the majority of students in this study struggled to demonstrate strong statistical knowledge, those who took the non-credit statistics course performed comparably on a measure of statistics ability as their peers who completed the statistics pre-requisite elsewhere. However, the overall low ability to apply statistics and high levels of anxiety are concerning.

Future research should explore the experiences of students who have passed an introductory statistics course and maintained their statistical literacy (Ramirez et al., 2012). What helped them develop this lasting competence? Given that professional disciplines prepare students for practice, the functional context, or academic learning that carries over to the field (Barnett \& Ceci, 2002), is most important. Once in professional settings, graduates may face barriers in using research and statistics to inform and evaluate their practice, such as a lack of time and inconsistent access to the literature (Edmond, Megivern, Williams, Rochman, \& Howard, 2006). Social work educators can help students become aware of these realities of practice, and become intentional and resourceful in retaining their knowledge, maintaining their skills, and locating statistical resources. Social work educators need to develop an understanding of approaches for effectively socializing students to value and develop enduring competence with statistics.

\section{References}

Barnett, S., \& Ceci, S. (2002). When and where do we apply what we learn?: A taxonomy for far transfer. Psychological Bulletin, 128(4), 612-637. doi: https://doi.org/10.1037/0033-2909.128.4.612

Barretti, M. (2004). What do we know about the professional socialization of our students? Journal of Social Work Education, 40, 255-283. doi: https://dx.doi.org/10.1080/10437797.2004.10778493

Bolen, R. (2006). Utilizing web-based databases to introduce social work content in research statistics courses. Social Work Education, 25, 17-27. doi: https://doi.org/10.1080/02615470500477805

Bolin, B., Lee, K., GlenMaye, L., \& Yoon, D. (2012). Impact of research orientation on attitudes toward research of social work students. Journal of Social Work Education, 48(2), 223-243. doi: https://doi.org/10.5175/JSWE.2012.200900120

Calderwood, K. (2002). Incorporating multiple epistemologies into teaching statistics to social work students. Journal of Teaching in Social Work, 22, 17-32. doi: https://doi.org/10.1300/J067v22n01_03 
Capshew, T. (2005). Motivating social work students in statistics courses. Social Work Education, 248, 857-868. doi: https://doi.org/10.1080/02615470500342207

Council on Social Work Education. (2015). Educational policy and accreditation standards. Alexandria, VA: Author.

Curran, E., Carlson, K., \& Celotta, D. (2013). Changing attitudes and facilitating understanding in the undergraduate statistics classroom: A collaborative learning approach. Journal of the Scholarship of Teaching and Learning, 13(2), 49-71.

Daniel, F., \& Braasch, J. (2013). Application exercises improve transfer of statistical knowledge in real-world situations. Teaching of Psychology, 403, 200-207. doi: https://doi.org/10.1177/0098628313487462

Davis, S. (2003). Statistics anxiety among female African American graduate-level social work students. Journal of Teaching in Social Work, 23(3-4), 143-158. doi: https://doi.org/10.1300/J067v23n03_12

Davis, A., \& Mirick. R. G. (2015). MSW students' perceptions of relevance and application of statistics: Implications for field education. Journal of Teaching in Social Work, 35(3), 317-336. doi: https://doi.org/10.1080/08841233.2015.1040531

Edmond, T., Megivern, D., Williams, C., Rochman, E., \& Howard, M. (2006). Integrating evidence-based practice and social work field education. Journal of Social Work Education, 42(2), 377-396. doi: https://doi.org/10.5175/JSWE.2006.200404115

Elliott, W., Choi, E., \& Friedline, T. (2013). Online statistics labs in MSW research methods courses: Reducing reluctance toward statistics. Journal of Social Work Education, 491, 81-95. doi: https://doi.org/10.1080/10437797.2013.755095

Gelman, C. (2004). Anxiety experienced by foundation-year MSW students entering field placement: Implications for admissions, curriculum, and field education. Journal of Social Work Education, 401, 39-54. doi: https://doi.org/10.1080/10437797.2004.10778478

Goldstein, G. (2007). Using classroom assessment techniques in an introductory statistics class. College Teaching, 552, 77-82. doi: https://doi.org/10.3200/CTCH.55.2.77-82

Gordon, S. (2004). Understanding students' experiences of statistics in a service course. Statistics Education Research Journal, 31, 40-59.

Harder, J. (2010). Overcoming MSW students' reluctance to engage in research. Journal of Teaching in Social Work, 30(2), 195-209. doi: https://doi.org/10.1080/08841231003705404

IBM Corp. (2012). Released 2012. IBM SPSS Statistics for Windows, Version 21.0. Armonk, NY: IBM Corp.

Junius, P., \& Sidell, N. (2009). Dispelling fear and loathing: Engaging mathematically challenged students to learn statistics. Journal of Baccalaureate Social Work, 142, 49-61. 
Knight, C. (2015). Social work students' use of the peer-reviewed literature and engagement in evidence-based practice. Journal of Social Work Education, 51(2), 250-269. doi: https://doi.org/10.1080/10437797.2015.1012924

Lalayants, M. (2012). Overcoming graduate students' negative perceptions of statistics. Journal of Teaching in Social Work, 324, 356-375. doi: https://doi.org/10.1080/08841233.2012.705259

Lesser, L. M. (2007). Critical values and transforming data: Teaching statistics with social justice. Journal of Statistics Education, 15(1), 1-21.

Lesser, L. M., Wall, A., Carver, R., Pearl, D. K., Martin, N., Kuiper, S.,...Webber, J. J., III. (2013). Using fun in the statistics classroom: An exploratory study of college instructors' hesitations and motivations. Journal of Statistics Education, 21(1), 1-33. Retrieved from www.amstat.org/publications/jse/v21n1/lesser.pdf

Macheski, G., Buhrmann, J., Lowney, K., \& Bush, M. (2008). Overcoming student disengagement and anxiety in theory, methods, and statistics courses by building a community of learners. Teaching Sociology, 361, 42-48. doi: https://doi.org/10.1177/0092055X0803600106

Marson, S. (2007). Three empirical strategies for teaching statistics. Journal of Teaching in Social Work, 273, 199-213. doi: https://doi.org/10.1300/J067v27n03_13

McGrath, A. (2014). Just checking in the effect of an office hour meeting and learning reflection in an introductory statistics course. Teaching of Psychology, 411, 83-87. doi: https://doi.org/10.1177/0098628313514186

Moran, T. (2005). The sociology of teaching graduate statistics. Teaching Sociology, 33, 263-271. doi: https://doi.org/10.1177/0092055X0503300303

National Association of Social Workers. (2008). Code of ethics. Washington, DC: Author.

Neumann, D., Hood, M., \& Neumann, M. (2009). Statistics? You must be joking: The application and evaluation of humor when teaching statistics. Journal of Statistics Education, 172, 1-16.

Onwuegbuzie, A. J., \& Wilson, V. A. (2003). Statistics anxiety: Nature, etiology, antecedents, effects, and treatments: A comprehensive review of the literature. Teaching in Higher Education, 8(2), 195-209. doi: https://doi.org/10.1080/1356251032000052447

Pan, W., \& Tang, M. (2005). Students' perceptions on factors of statistics anxiety and instructional strategies. Journal of Instructional Psychology, 32(3), 205-214.

Pryczak, F. (2014). Making sense of statistics: A conceptual overview. New York: Routledge.

Rabin, L., \& Nutter-Upham, K. (2010). Introduction of a journal excerpt activity improves undergraduate students' performance in statistics. College Teaching, 584, 156-160. doi: https://doi.org/10.1080/87567555.2010.484034 
Ramirez, C., Schau, C., \& Emmioglu, E. (2012). The importance of attitudes in statistics education. Statistics Education Research Journal, 112, 57-71.

Secret, M., Ford, J., \& Rompf. E. (2003). Undergraduate research courses: A closer look reveals complex social work student attitudes. Journal of Social Work Education, 393, 411-422. doi: https://doi.org/10.1080/10437797.2003.10779146

Sizemore, O., \& Lewandowski, G. (2009). Learning might not equal liking: Research methods course changes knowledge but not attitudes. Teaching of Psychology, 362, 90-95. doi: https://doi.org/10.1080/00986280902739727

Smith, L., Shon, H., \& Santiago, R. (2011). Audience response systems: Using 'clickers' to enhance BSW education. Journal of Technology in Human Services, 292, 120-132. doi: https://doi.org/10.1080/15228835.2011.587737

Stickels, J. W., \& Dobbs, R. R. (2007). Helping alleviate statistical anxiety with computer aided statistical classes. Journal of Scholarship of Teaching and Learning, $7(1), 1-15$.

Thomas, L. (2008). Analogical instruction in statistics: Implications for social work educators. Journal of Teaching in Social Work, 28(1/2), 247-271. doi: https://doi.org/10.1080/08841230802179357

Wells, M. (2006). Making statistics 'real' for social work students. Journal of Social Work Education, 422, 397-404. doi: https://doi.org/10.5175/JSWE.2006.200400466

Wilson, S. (2013). The flipped class: A method to address the challenges of an undergraduate statistics course. Teaching of Psychology, 403, 193-199. doi: https://doi.org/10.1177/0098628313487461

Author note: Address correspondence to: Ashley Davis, PhD, MSW, Wheelock College, Department of Social Work, 200 Riverway, Boston, MA, 02215. adavis@wheelock.edu 


\section{Appendix A: Application Score Questions}

1. A social worker helps people who are unemployed transition back to work. She tracks how long it takes people to get a job again and finds a mean of 12 months and a median of 6 months. Why might the mean and median be different values?

$\square$ Outliers affect the mean, but not the median.

The median is always less than the mean.

$\square$ The median reflects the frequently occurring value.

All of the above.

2. A social worker learns that there is a significant strong negative correlation between number of days of exercise and severity of Depression (as measured by a standardized instrument). What does this finding mean?

$\square$ People who exercise more frequently are more likely to experience severe Depression.

$\square$ People who exercise less frequently are more likely to experience Depression.

$\square$ Frequency of exercising and severity of Depression are not related.

3. Three social workers develop an all-day training on the best practices for suicide assessment and prevention. The social workers want to see how effective the training is at increasing participants' knowledge, confidence, and competence around suicide assessment and prevention.

Prior to the start of the training, participants take a pretest, measuring these three areas. At the end of the day, after the training, the participants take a post-test.

A t-test was run to look at the change in scores from pretest to posttest for each participant. The table below illustrates the means and standard deviations for the participants' scores as well as the mean difference between participants' pre and post-test scores and the standard deviation of this difference. Higher scores indicated higher levels of knowledge, competence, and confidence.

Training participants' scores

\begin{tabular}{|l|l|l|l|l|l|}
\hline & Mean & SD & $\begin{array}{l}\text { Mean of the differences } \\
\text { between pre and post tests }\end{array}$ & $\begin{array}{l}\text { SD of the difference } \\
\text { between the mean scores }\end{array}$ & $\mathrm{n}$ \\
\hline Pre-test & 131.2 & 16.64 & 26.8 & 15.34 & 59 \\
\hline Post-test & 158.0 & 14.32 & & & 5 \\
\hline
\end{tabular}

After conducting a t-test, she learns: $\mathrm{t}=-13.421, \mathrm{p}<.001$.

Based on the example above, answer the following questions.

4. Is the difference in mean scores statistically significant?

$\square$ Yes
$\square$ No
$\square$ Cannot determine

5. Why?

6. Based on these findings, can they conclude that the training is effective?

$\square$ Yes
$\square$ No
$\square$ Cannot determine

7. Why? 